\title{
Drug-Carrying Amino Silane Coated Magnetic Nanoparticles as Potential Vehicles for Delivery of Antibiotics
}

\author{
Mohammad Hossein Mashhadizadeh* and Mitra Amoli-Diva
}

Faculty of Chemistry, Tarbiat Moalem University, Tehran, Iran

\begin{abstract}
Drug carrying amino silane coated magnetic nanoparticles were synthesized and used as a flexible magnetic targeted delivery of antibiotics. Magnetic nanoparticles were prepared by chemical co-precipitation method and the surfaces were coated by 3-aminopropyletriethoxy silane. The characteristics of the nanoparticles were examined by Transmission Electron Microscope (TEM), X-Ray Diffraction (XRD), elemental analysis, and Fourier Transform Infrared (FTIR). TEM shows the average size of $8.6 \mathrm{~nm}$ in diameter for modified nanoparticles, XRD confirms the formation of nanoparticles, elemental analysis indicates that amino silane molecules have been bond onto the surface of the nanoparticles and FTIR spectra confirm that APTES and the drugs were bond onto the surface of the nanoparticles. Drug delivery behavior of the amino silane coated MNPs was studied by selecting ofloxacin and ciprofloxacin as model drugs. Effects of $\mathrm{pH}$ and temperature on the release of the drugs were studied. The drug loading efficiency was found 93.4 and $91.1 \%$ for ofloxacin and ciprofloxacin, respectively. Release kinetics of both drugs showed that at $\mathrm{pH} 5.5$ approximately $22 \%$ and $27.13 \%$ were released while at $\mathrm{pH} 7.2$ releases occur with nearly $81.7 \%$ and $98.78 \%$ for ofloxacin and ciprofloxacin, respectively. In order to evaluate the release kinetics and mechanism of the drugs, different mathematical release models were applied to the released data at $\mathrm{pH}$ 7.2. The data was best fitted to the first-order and Higuchi an equations for ciprofloxacin and ofloxacin respectively, which revealed diffusion controlled and Fickian transport.
\end{abstract}

Keywords: Magnetic nanoparticles; Drug delivery; Antibiotic; Ofloxacin; Ciprofloxacin; Amino silane

\section{Introduction}

Drug delivery is an intriguing field of research that has captured the interest of researchers because delivering a medicine to its site of therapeutic action is one of the main limitations of pharmaceutical and biotechnology industries [1]. In the last two decades, nanostructure materials such as nanoparticles have attracted a great deal of interest in drug delivery due to their unique size and physical properties [1,2].

Many types of Nanoparticles (NPs) can be used as drug-delivery systems and these can be formulated from diverse materials with unique architectures to serve as a possible drug-delivery vehicle to treat a particular disease. Drugs can be loaded onto NPs by various methods, such as encapsulation [3], surface attachment [4], or entrapment [5]. NPs due to their small size can efficiently penetrate across barriers through small capillaries into individual cells, thus allowing efficient drug accumulation at the target site. Therefore, the unwanted side effects of the therapeutic agent are reduced and the therapeutic efficacy is enhanced [4].

To improve the stability of NPs, polymers, surfactants or other modifiers are often adsorbed or grafted to the particles, forming a layer that generates an effective repulsive force between NPs and prevents flocculation [6].

Magnetic particles ranging from the nanometer to micrometer scale are being used in an increasing number of medical applications. The important properties of magnetic nanoparticles for medical applications are nontoxicity, injectability, and high-level accumulation in the target tissue or organ.

Drug delivery may be immensely benefited by use of (Magnetic Nanoparticles) MNPs because these particles have the ability to target a specific site, such as a tumor, thereby reducing the systemic distribution of cytotoxic compounds in vivo and enhancing drug uptake at the target site, resulting in effective treatment at lower doses [7,8]. In the preparation of colloidal MNPs, the stability of the colloid is of utmost importance. Magnetic iron oxide particles without any surface coatings have hydrophobic surfaces with a large surface area to volume ratio, this leads to particles agglomeration and formation of large clusters, resulting in increased particle size. This inherent aggregation behavior of MNPs is a crucial limiting factor that reduces the intrinsic super paramagnetic properties and triggers the opsonization process [9]. Therefore, to minimize the aggregation, it is necessary to engineer the surface of the MNPs.

Silica derivatives are often employed as coating material over the surface of MNPs [10]. It is chemically inert and can weaken the particle-particle magnetic bipolar interaction. On the other hand, one of the preferred functional groups for bonding different bioactive compounds is amino group. Both can provide by using (3-aminopropyltriethoxysilane) APTES as coating material [11,12]. APTES has been reacting with nanoparticle surfaces in different nonpolar and polar solvents. Influence of different solvents on the silanization of silica coated nanoparticles showed that the process of APTES bonding was the most efficient in water [13]. APTES hydrolyzes in the presence of water and the silanol group's condensate with metal hydroxyl groups on the nanoparticles surface. The modified magnetic nanoparticles with amino-silane shell are non-cytotoxic and injectable

*Corresponding author: Mohammad Hossein Mashhadizadeh, Faculty of Chemistry, Tarbiat Moalem University, Tehran, Iran, Tel: +98 21 88848949; Fax: +98 21 88820993; E-mail: mashhadizadeh@tmu.ac.ir

Received April 01, 2012; Accepted May 27, 2012; Published June 01, 2012

Citation: Mashhadizadeh MH, Amoli-Diva M (2012) Drug-Carrying Amino Silane Coated Magnetic Nanoparticles as Potential Vehicles for Delivery of Antibiotics. J Nanomed Nanotechol 3:139. doi:10.4172/2157-7439.1000139

Copyright: (c) 2012 Mashhadizadeh $\mathrm{MH}$, et al. This is an open-access article distributed under the terms of the Creative Commons Attribution License, which permits unrestricted use, distribution, and reproduction in any medium, provided the original author and source are credited. 
[14]. These super paramagnetic particles are able to bind to drugs, metals and biological molecules, to use as drug delivery vehicles for controlled drug delivery or to serve as separating materials to remove them from medium by magnetic separation procedures.

In the present study, we report the preparation of super paramagnetic nanoparticles were coated with 3-amino propyltriethoxysilane (APTES), $\mathrm{NH}_{2}\left(\mathrm{CH}_{2}\right)_{3} \mathrm{Si}\left(\mathrm{OC}_{2} \mathrm{H}_{5}\right)_{3}$. This organo silane bind to $\mathrm{Fe}_{3} \mathrm{O}_{4}$ nanoparticles and the drug delivery behavior of the modified nanoparticles was studied by selecting two antibiotics including ofloxacin and ciprofloxacin (Figure 1) as model drugs. The loading characteristics and release behavior of the drugs were studied and the effect of $\mathrm{pH}$ and temperature on the release was determined. Furthermore, kinetic modeling of release for the ofloxacin and ciprofloxacin was evaluated using common mathematical equations. The behavior of drug release from nanoparticles indicated that the prepared nanoparticles could be effectively used as drug delivery system for controlled released of the antibiotics and the drug release could be effectively sustained.

\section{Experimental}

\section{Materials and reagents}

Iron (III) chloride hexahydrate $\left(\mathrm{FeCl}_{3}{ }^{\star} 6 \mathrm{H}_{2} \mathrm{O}\right)$, Iron (II) chloride tetrahydrate $\left(\mathrm{FeCl}_{2}{ }^{\star} 4 \mathrm{H}_{2} \mathrm{O}\right)$, aqueous ammonia (25\%), 3-amino propyltriethoxysilane (APTES), methanol, acetic acid, sodium acetate trihydrate $\left(\mathrm{CH}_{3} \mathrm{COONa}^{\star} 3 \mathrm{H}_{2} \mathrm{O}\right)$, sodium hydroxide, potassium hydrogen phosphate, and Glycerol (about $87 \%$ ), in analytical grade were purchased from Merck Company (Darmstadt, Germany). Ciprofloxacin and ofloxacin were received as a gift from Faculty of<smiles>O=C(O)c1cn(C2CC2)c2cc(N3CCNCC3)c(F)cc2c1=O</smiles>

(a)

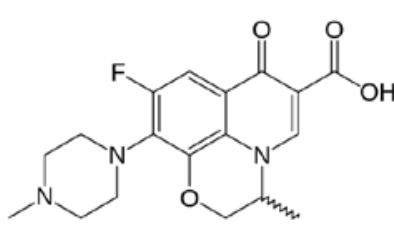

(b)
Figure 1: Chemical structure of (a) Ciprofloxacin and (b) Ofloxacin
Pharmacy, Tehran University. All the chemicals were analytical grade and used without further purification. Deionized water was used throughout the experiment.

\section{Instrumentation}

UV-Vis spectra of released drugs and other solutions were carried out by UV-240 Shimadzu UV-Vis spectrophotometer. A Metrohm 827 $\mathrm{pH}$ meter was used for measuring and adjusting the $\mathrm{pH}$ of the solutions. Phase Characterization was performed using Phillips PW-1800 X-Ray diffraction. Characterization of $\mathrm{Fe}_{3} \mathrm{O}_{4}$ nanoparticles and APTES- $\mathrm{Fe}_{3} \mathrm{O}_{4}$ nanoparticles were carried out by Perkin Elmer FTIR spectrometer, Spectrum one Bv5.3.0. A CM120 electron microscope PW6031 Transmission electron microscope was used for characterization of particle size and morphology of modified nanoparticles. Elemental analysis was performed onto the APTES-coated MNPs using Perkin Elmer 2400 SERESE II. RC $0.45 \mu \mathrm{m}$ filters were used to filter the drug solutions before recording their UV-Vis spectra. A Memmert WB10 water bath was used to precise control of the temperature.

\section{Preparation of silane coated magnetite nanoparticles}

The magnetic nanoparticles were prepared according to our previous work [15]. Briefly, $11.68 \mathrm{~g}$ of $\mathrm{FeCl}_{3}{ }^{\star} 6 \mathrm{H}_{2} \mathrm{O}$ and $4.3 \mathrm{~g} \mathrm{FeCl}_{2}{ }^{\star} 4 \mathrm{H}_{2} \mathrm{O}$ were dissolved in $200 \mathrm{~mL}$ deionized water under nitrogen atmosphere with vigorous stirring at $80^{\circ} \mathrm{C}$. Then $45 \mathrm{~mL}$ of aqueous ammonia solution (25\%) was added. The color of solution was turned from dark orange to the black immediately. The precipitates were washed three times with deionized water and twice with $0.02 \mathrm{M}$ sodium chloride. The prepared magnetite suspension was placed in $250 \mathrm{~mL}$ round flask and allowed to settle to remove the supernatant. Then $80 \mathrm{~mL}$ aqueous solution of $10 \%$ (v/v) APTES and $40 \mathrm{ml}$ glycerol were added to the mixture and heated at $90^{\circ} \mathrm{C}$ for $2 \mathrm{~h}$ under nitrogen atmosphere with stirring. After cooling to room temperature the suspension was washed sequentially with $200 \mathrm{~mL}$ deionized water (three times), $100 \mathrm{~mL}$ methanol (five times), and $200 \mathrm{~mL}$ deionized water (three times). The prepared silane coated MNPs were stored in deionized water. Figure 2 shows the schematic of the procedure.

\section{Characterization}

The size and morphology of modified nanoparticles were obtained using Transmission Electron Microscope (TEM) and the images were obtained by placing one drop of each sample on a carbon plate. The

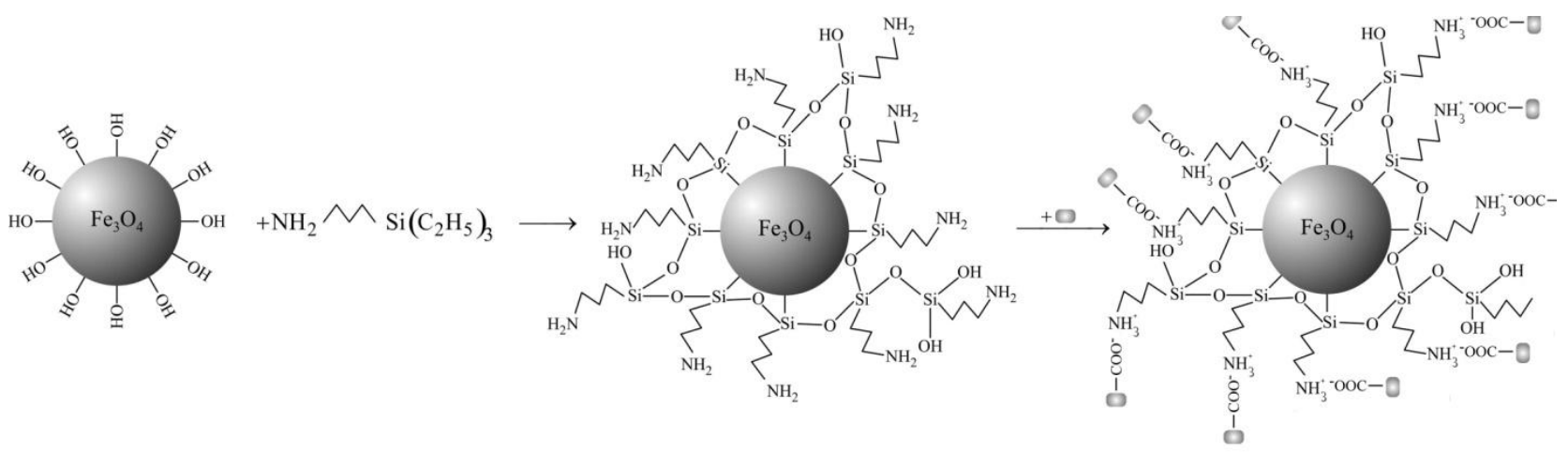

○-co- Drug $\left.\quad \mathrm{Fe}_{3} \mathrm{O}_{4}\right) \mathrm{Fe}_{3} \mathrm{O}_{4}$ Nanoparticle

Figure 2: Schematic illustration of preparation of the coated magnetic nanoparticles. 
average size of silane coated nanoparticles based on more than 300 particles was measured from TEM images. Phase Characterization was performed by $\mathrm{X}$-Ray diffraction using $\mathrm{Cu} \mathrm{K}_{\alpha}$ radiation source $(\lambda=1.540598)$ with reflection scan mode. Surface modification and drug loading of magnetic nanoparticles were analyzed using Fourier transform infrared spectroscopy with $4 \mathrm{~cm}^{-1}$ resolution. The FTIR spectra were measured in the $400-4000 \mathrm{~cm}^{-1}$ region for sample dispersed in $\mathrm{KBr}$ pellets. Elemental analysis was performed onto the APTES-coated MNPs to confirm the coating of amino silane modifier.

\section{Drug loading}

The drug loading was carried out by dispersing $168 \mathrm{mg}$ of magnetic nanoparticles in $20 \mathrm{~mL}$ of methanolic solution of the drug with the concentration in the range of 8.4-840 $\mu \mathrm{g} \mathrm{mL}^{-1}$ for both ciprofloxacin and ofloxacin. The solutions were stirred for $5 \mathrm{~h}$ at room temperature to facilitate drug uptake. At appropriate time intervals, the MNPs were collected from the solution by an external magnet. The supernatant was withdrawn from the solutions and filtered. The concentrations of residual drugs were measured spectrophotometerically at 270 and 287 $\mathrm{nm}$ for ciprofloxacin and ofloxacin, respectively. The solutions obtained from the unloaded nanoparticles in the same experimental conditions were used as blank. Ciprofloxacin and ofloxacin concentrations loaded to the nanoparticles were determined by measuring absorbance against a standard curves were constructed with different concentrations of the drugs (1-14 $\left.\mu \mathrm{g} \mathrm{mL}^{-1}\right)$ with the same conditions as the samples. If needed, appropriate dilutions were done to make the concentration of the solutions in the range of calibration curves. After each measurement, MNPs were redispersed for further drug loading. After a certain adsorption time, there were no further changes in the concentrations of the drugs which mean the loading capacity of MNPs were saturated. The percentage of loading efficiency at each predetermined time was calculated as the ratio of difference between the initial drug concentration and the drug concentration in the supernatant (drug loss) to the initial drug concentration, as followed,

$$
\text { Loading efficiency } \%=\frac{\text { initial drug conc. }- \text { drug loss }}{\text { initial drug conc. }} \times 100 \%
$$

The drug loaded nanoparticles were then magnetically separated, rinsed with $100 \mathrm{~mL}$ methanol three times and dried in vacuum oven at $45^{\circ} \mathrm{C}$.

\section{Loading capacity}

To determine the loading capacity of prepared nanoparticles, 168 $\mathrm{mg}$ of modified nanoparticles were dispersed in $20 \mathrm{~mL}$ methanolic solution of each drug with the different concentration in the range of 8.4-840 $\mu \mathrm{g} \mathrm{mL}^{-1}$ and left the solutions for further adsorption. After 2 and 5 hours, the magnetic nanoparticles were removed from the solution by magnet and the concentrations of residual drugs were measured by UV-Vis spectrophotometer. The loading capacity (drug content) of MNPs were calculated by following equation,

$$
\text { Loading capacity } \%=\frac{\mathrm{mg}_{(\text {drug loaded })}}{\mathrm{mg}_{\text {(nanoparticles) }}} \times 100 \%
$$

where, $\mathrm{mg}_{\text {(drug loaded) }}$ is the weight of the drug loaded to the nanoparticles and $\mathrm{mg}_{\text {(nanoparticles) }}$ is the gross weight of the nanoparticles.

\section{In vitro drug release}

The in vitro release study of drug-loaded nanoparticles were carried out at $37^{\circ} \mathrm{C}$ in acetate buffered solution at $\mathrm{pH} 5.5$ and phosphate buffered solution at $\mathrm{pH} 7.0$ under stirring. $1.0017 \mathrm{~g}$ of drug loaded MNPs were dispersed in $50 \mathrm{ml}$ of each buffer solution. The tube was shaken in the shaking water bath at $37^{\circ} \mathrm{C}$. At predetermined time intervals, 6 $\mathrm{ml}$ of supernatant was withdrawn from the solutions and filtered to remove any nanoparticles may exist in the supernatant. Absorbance of the collected solution was measured at 270 and $287 \mathrm{~nm}$ to determine the drug concentration of ciprofloxacin and ofloxacin respectively. The solutions obtained from the unloaded nanoparticles in the same experimental conditions were used as blank. The concentrations of two drugs were determined by measuring the absorbance against the standard curves. The cumulative release of drugs were expressed by following equation,

$$
\text { Cumulative release }(\%)=\frac{\mathrm{mg}_{(\text {drug released })}}{\mathrm{mg}_{(\text {total drug })}} \times 100
$$

where, $\mathrm{mg}_{\text {(drug released) }}$ is the amount of drug released at the time $\mathrm{t}$ and $\mathrm{mg}_{\text {(total drug) }}$ is the total amount of drug present in drug loaded magnetic nanoparticles.

\section{Kinetic modeling of drug release}

Many kinetic models were describing the overall release of drug from the dosage forms because qualitative and quantitative changes in a formulation may alter drug release and in vivo performance. Developing tools that facilitate product development by reducing the necessary of bio-studies was always desirable. A class of methods to investigate the kinetics of drug release from controlled release formulation is model dependent methods which are based on different mathematical functions, which describe the release profile. Various kinetic models used are i) the zero-order release rate which describes the system where the drug release rate is independent of its concentration, ii) the first order rate describes the release from system where release is concentration dependent (Bourne), iii) Higuchi model which describes the release of drugs from insoluble matrix as a square root of time, which is dependent process based on fickian diffusion and iv) Hixson-Crowl cube root law which describes the drug release from system where there is a change in surface area and diameter of particles or tablets. In this study, the release profile of each drug was fitted to these models to ascertain the kinetic modeling of drug release.

\section{Results and Discussion}

\section{Characterization}

The magnetic nanoparticles were prepared by co-precipitation process in an aqueous medium through the reaction [16]:

$$
\mathrm{Fe}^{2+}+2 \mathrm{Fe}^{3+}+8 \mathrm{OH}^{-} \rightarrow \mathrm{Fe}_{3} \mathrm{O}_{4}+4 \mathrm{H}_{2} \mathrm{O}
$$

Magnetic nanoparticles are very sensitive to presence of oxygen in air, some of them may undergo oxidation or phase transition (for example the maghemite, $\gamma-\mathrm{Fe}_{2} \mathrm{O}_{3}$ ). Thus the process was done in the atmosphere of nitrogen. The difficulty in preparing MNPs by chemical co-precipitation is the tendency of MNPs to agglomeration. This problem can be solved by surface modification. The process of surface modification is done by silanization reaction. The final product was dense, black and exhibit strong magnetization under magnetic field. TEM micrograph of silane-coated iron oxide nanoparticles was shown in Figure 3. The size distribution was determined by measuring diameters of more than three hundred NPs randomly selected on the TEM micrographs which shown in Figure 4. Although the pristine 
$\mathrm{Fe}_{3} \mathrm{O}_{4}$ NPs were polydisperse and seriously aggregated commonly [17], after surface modification by APTES, the particle size is almost uniform and has spherical shape with an average size of $8.6 \pm 1.6 \mathrm{~nm}$.

The crystalline phase of APTES-coated MNPs was characterized by observing XRD pattern of the sample. Figure 5 shows the XRD pattern of pristine APTES-coated $\mathrm{Fe}_{3} \mathrm{O}_{4}$ NPs. A series of characteristic peak for $\mathrm{Fe}_{3} \mathrm{O}_{4}$ nanoparticles $(2 \theta=30.10,35.53,43.08,57.10$ and 62.73$)$ were observed in the sample. These peaks are consistent with the standard pattern of $\mathrm{Fe}_{3} \mathrm{O}_{4}$ with a cubic structure [18]. The result indicates that the modification did not change the crystal structure of the $\mathrm{Fe}_{3} \mathrm{O}_{4} \mathrm{NPs}$. In addition, in the synthesis of $\mathrm{Fe}_{3} \mathrm{O}_{4}$ nanoparticles (magnetite), some maghemite $\left(\gamma-\mathrm{Fe}_{2} \mathrm{O}_{3}\right)$ often formed, showing the similar XRD pattern to magnetite. From the peaks, it can be considered that separate maghemite is not present in the samples.

In order to confirm the coating of the magnetite surface through the silanization reaction, FTIR spectroscopy was used. Figure 6 shows the FTIR spectra of the $\mathrm{Fe}_{3} \mathrm{O}_{4}$ and APTES- $\mathrm{Fe}_{3} \mathrm{O}_{4}$ nanoparticles. For the $\mathrm{Fe}_{3} \mathrm{O}_{4}$ nanoparticles, the characteristic absorption peaks at 579 and 636 $\mathrm{cm}^{-1}$ are attributed to the Fe-O structure [19]. APTES is absorbed on the magnetite nanoparticles surfaces by $\mathrm{Fe}-\mathrm{O}-\mathrm{Si}$ bands, because of the absorption band corresponded to this band appears at around 587.6 $\mathrm{cm}^{-1}$ and therefore overlaps with the $\mathrm{Fe}-\mathrm{O}$ band, latest band cannot be seen in FTIR spectrum. The band at 1113.8 due to the stretching vibration of $\mathrm{Si}-\mathrm{O}$ band and the two bands at 3305.6 and $1662.5 \mathrm{~cm}^{-1}$ due to the N-H stretching vibration and $\mathrm{NH}_{2}$ bending mode of free $\mathrm{NH}_{2}$ groups, confirm the existence of APTES.

FTIR was further extended to study the conjugation of ciprofloxacin and ofloxacin. FTIR of pure ciprofloxacin and ciprofloxacin-conjugated APTES-coated iron oxide nanoparticles are presented in Figure 7.

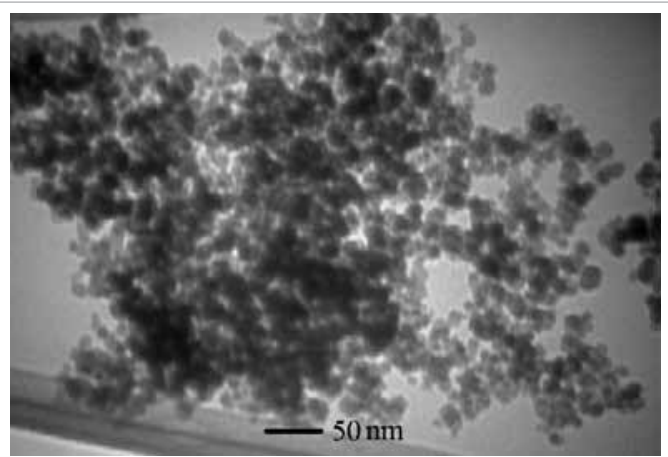

Figure 3: TEM image of APTES-coated $\mathrm{Fe}_{3} \mathrm{O}_{4}$ nanoparticles with average diameter of $8.6 \mathrm{~nm}$.

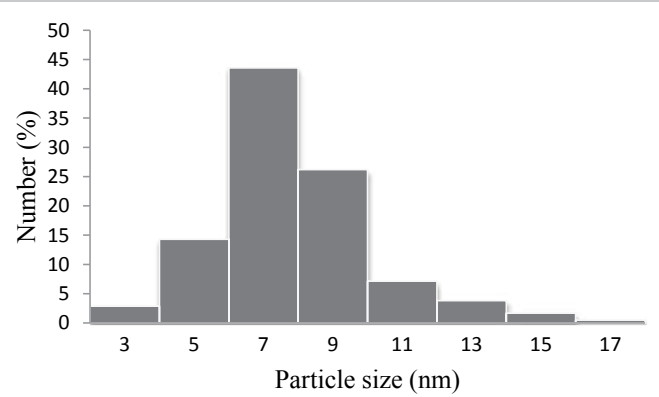

Figure 4: Size distribution of APTES- coated magnetic nanoparticles.

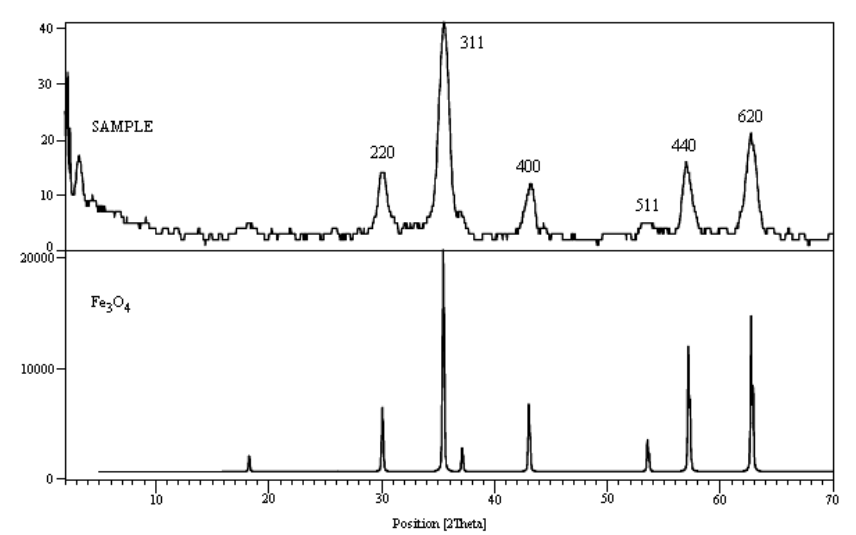

Figure 5: XRD patterns of (a) $\mathrm{Fe}_{3} \mathrm{O}_{4}$ nanoparticles and (b) APTES coated$\mathrm{Fe}_{3} \mathrm{O}_{4}$ nanoparticles.

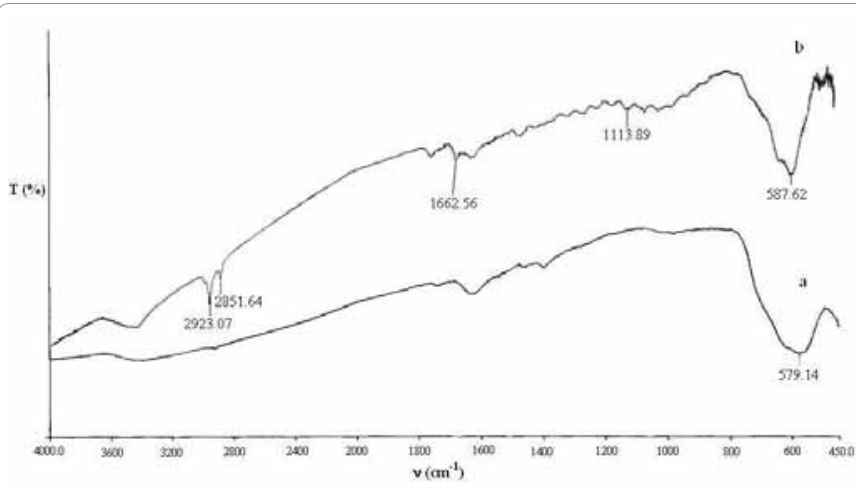

Figure 6: FTIR spectra of (a) $\mathrm{Fe}_{3} \mathrm{O}_{4}$ nanoparticles, and (b) APTES coated$\mathrm{Fe}_{3} \mathrm{O}_{4}$ nanoparticles.

FTIR spectrum of pure ciprofloxacin is complicated because of many absorption modes of several groups. But some of useful absorption bands mentioned here. FTIR spectra of pure ciprofloxacin shows peaks at 3378 and $1708 \mathrm{~cm}^{-1}$ due to free $-\mathrm{OH}$ and $\mathrm{C}=\mathrm{O}$ stretching vibration of carboxylic acid groups, 3528 and $1624 \mathrm{~cm}^{-1}$ due to stretching and bending vibration of amine $-\mathrm{NH}$ respectively, and $987 \mathrm{~cm}^{-1}$ due to $\mathrm{C}-\mathrm{F}$ stretching vibration.

In ciprofloxacin-conjugated magnetic nanocomposite, existence of many drug peaks such as $\mathrm{C}=\mathrm{C}$ stretching vibration peak of aromatic groups at 1616 and 1465 beside existence of two peaks at 1632 and 1742 which show $-\mathrm{NH}$ and $-\mathrm{C}=\mathrm{O}$ stretching vibration of carboxylic group and a peak at $994 \mathrm{~cm}^{-1}$ which shows $\mathrm{C}-\mathrm{F}$ strong stretching vibration and moreover, the existence of the characteristic strong band for $\mathrm{Fe}_{3} \mathrm{O}_{4}$ nanoparticles at $558 \mathrm{~cm}^{-1}$ confirm the conjugation of drug to the magnetic carrier.

FTIR spectra of pure ofloxacin and ofloxacin-conjugated APTEScoated iron oxide nanoparticles are presented in Figure 8. Similar to ciprofloxacin, because of similarity in structure, FTIR spectrum of pure ofloxacin shows peaks at 3421 and $1713 \mathrm{~cm}^{-1}$ due to free $-\mathrm{OH}$ and $\mathrm{C}=\mathrm{O}$ stretching vibration of carboxylic acid groups, and $979 \mathrm{~cm}^{-1}$ due to $\mathrm{C}-\mathrm{F}$ stretching vibration. Existence of many drug peaks such as $\mathrm{C}=\mathrm{C}$ stretching vibration peak of aromatic groups at 1613 and 1467 beside existence of two peaks at 1637 and 1733 which show $-\mathrm{NH}$ and $-\mathrm{C}=\mathrm{O}$ stretching vibration of carboxylic group and a peak at $1002 \mathrm{~cm}^{-1}$ which 
shows $\mathrm{C}-\mathrm{F}$ strong stretching vibration and moreover, the existence of the characteristic strong band for $\mathrm{Fe}_{3} \mathrm{O}_{4}$ nanoparticles at $579 \mathrm{~cm}^{-1}$ confirms the conjugation of drug to magnetic carrier.

Elemental analysis was also used to confirm the coating of magnetic surface with amino silane modifier. According to the elemental analysis, the content of carbon, hydrogen and nitrogen in APTES-coated $\mathrm{Fe}_{3} \mathrm{O}_{4}$ NPs was $2.34 \% ; 0.50 \%$, and the $0.80 \%$, respectively. This confirms that the surface of magnetic nanoparticles was coated by APTES.

\section{Drugs loading}

The drug loading is attributed to the conjugation of $-\mathrm{COOH}$ groups in ciprofloxacin and ofloxacin to the surface $-\mathrm{NH}_{2}$ groups in APTES-coated nanoparticles. Ciprofloxacin and ofloxacin are of the fluoroquinone compounds which the presence of both the carboxyle and amine groups makes the acid-base behavior of these drugs influenced by the physico-chemical properties of the solvent. The reported values of $\mathrm{pK}_{\mathrm{a}}$ for ciprofloxacin are 6.2 and 8.8 for the carboxylic group and protonated amine group of piperazine [20] and for ofloxacine are 6.02

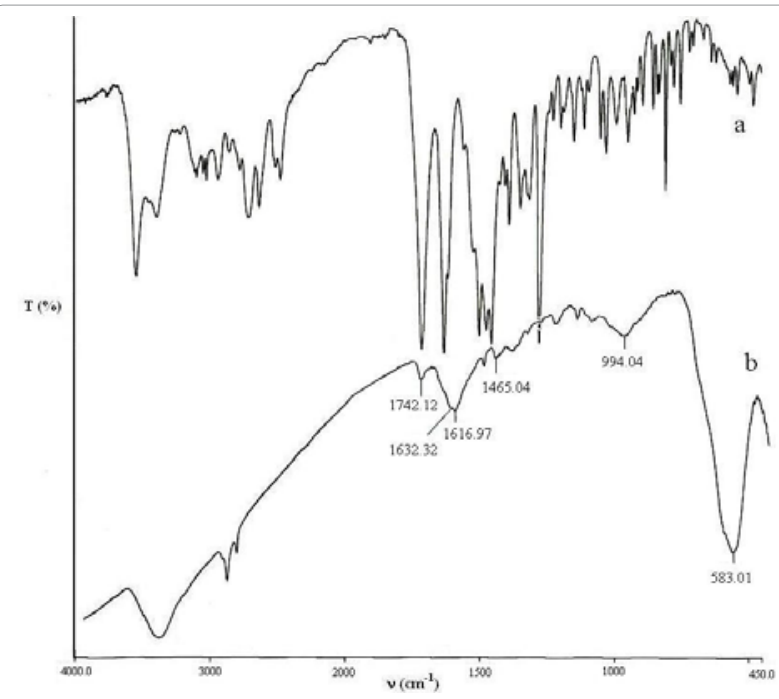

Figure 7: FTIR spectra of (a) Pure ciprofloxacin, and (b) Ciprofloxacinconjugated APTES- $\mathrm{Fe}_{3} \mathrm{O}_{4}$ nanoparticles.

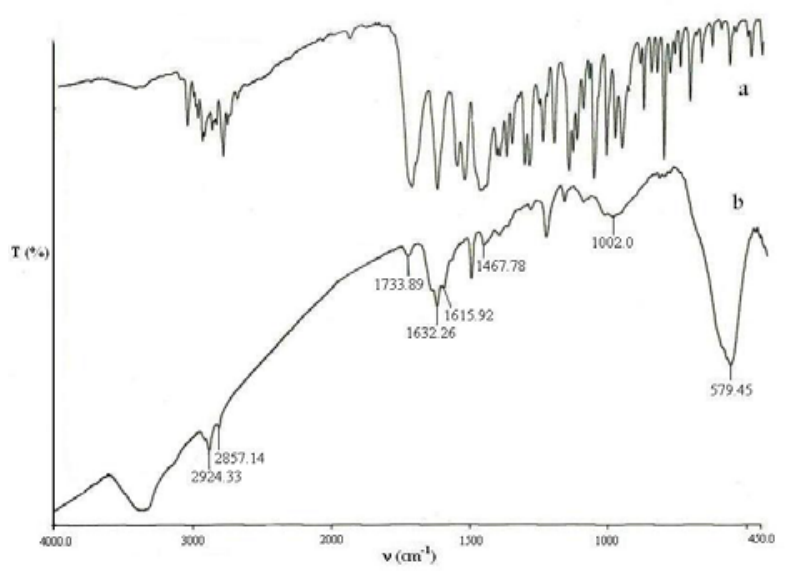

Figure 8: FTIR spectra of (a) Pure ofloxacin, and (b) Ofloxacin-conjugated APTES- $\mathrm{Fe}_{3} \mathrm{O}_{4}$ nanoparticles.

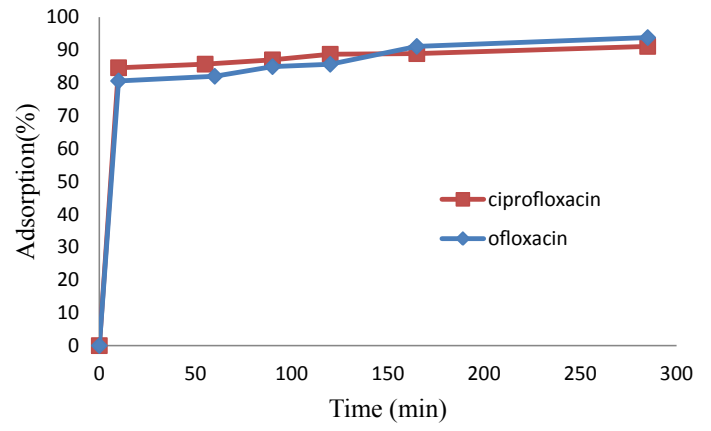

Figure 9: Time dependent loading of ciprofloxacin and ofloxacin. The drug concentration was $84 \mu \mathrm{g} \mathrm{mL}^{-1}$.

\begin{tabular}{|l|l|l|l|l|}
\hline Drug & Sample & $\begin{array}{l}\text { Feed } \\
\text { weight ratio } \\
\text { (MNPs:Drug) }\end{array}$ & $\begin{array}{l}\text { Loading } \\
\text { capacity (\%) }\end{array}$ & $\begin{array}{l}\text { Loading } \\
\text { efficiency }\end{array}$ \\
\hline & Sample I & $10: 1$ & 8.8 & 88.9 \\
\hline Ofloxacin & Sample II & $100: 1$ & 0.93 & 93.4 \\
\hline & Sample III & $1000: 1$ & 0.1 & 98.8 \\
\hline & Sample I & $10: 1$ & 6.2 & 81.3 \\
\hline Ciprofloxacin & Sample II & $100: 1$ & 0.89 & 91.1 \\
\hline & Sample III & $1000: 1$ & 0.1 & 97.3 \\
\hline
\end{tabular}

Table 1: The loading characteristic of modified magnetic nanoparticles.

and 8.22 [21]. Both drugs are zwitterions and neutral at $\mathrm{pH}$ 7. The $\mathrm{pK}_{\mathrm{a}}$ of APTES is 10.8 [22,23] and the electron-reach amine groups can bonded via $\mathrm{H}$-bonding with hydrogen donating groups of drugs like carboxyl or amines. In addition, APTES-coated nanoparticles have positive charge [24] and could be electrostatically bonded to the negative carboxyl group of the drugs.

Figure 9 shows the kinetics of each drug loading. The experiments carried out at room temperature and concentration of ciprofloxacin and ofloxacin was $84 \mu \mathrm{g} \mathrm{ml}^{-1}$. As seen, the drug loading was rapid in the first 10 min and nearly $84.6 \%$ of ciprofloxacin and $82.5 \%$ of ofloxacin were loaded. After $1 \mathrm{~h}$, the rate of drug loading decreased and finally about $91.1 \%$ of ciprofloxacin and $93.4 \%$ of ofloxacin were loaded in 5 h.

\section{Loading capacity}

The loading capacity of MNPs was determined by varying the weight ratio of MNPs to each drug. The loading characteristics of modified MNPs were summarized in Table 1. It can be seen that for ofloxacin, when the weight ratio (MNPs:Drug) was 10:1 (sample I), the loading capacity was above $8.8 \%$. If the weight ratio was 100:1 (sample II), the loading capacity decreased to about $1 \%$ (with loading efficiency about 93\%) and when the weight ratio was 1000:1 (sample III), and the loading capacity was $0.1 \%$ (with loading efficiency of about $99 \%$ ). As we expected, high absorption occurred due to high surface area of the MNPs in sample II and III that cause to nearly all the drug loaded to the nanoparticles. Similar results can be seen in ciprofloxacin-loaded magnetic nanoparticles and indicate good loading capacity of modified nanoparticles. This manner also can be seen in ciprofloxacin-loaded MNPs and indicate good loading capacity of modified nanoparticles. Similar results were observed previously [25-27].

Clearance of ofloxacin is fast and its plasma elimination half-life is approximately 4 to 5 hours. In addition, the elimination half-life of 
Page 6 of 7

Ciprofloxacin is about four hours. This means that every four hours, the level of Ciprofloxacin in your blood will drop by 50 percent of the previous level. Slow release of the drugs with lower content could be compensating this level decease.

\section{In vitro drug release studies}

For designing oral dosage forms, it must be considered that the $\mathrm{pH}$ of environment in gastrointestinal tract varying from acidic in the stomach to slightly alkaline in the intestine. However most literatures were focused on the drug carriers responding to a relatively large $\mathrm{pH}$ differences between 1.2 and 7.4 , and did not report their drug release behaviors at $\mathrm{pH}$ values slightly lower than 7.4. As we know, many factors may affect gastric $\mathrm{pH}$ although most commonly the gastric $\mathrm{pH}$ is lower than $\mathrm{pH} 3$, after ingestion of a meal the gastric acidity can vary over a wide range and be typically higher than $\mathrm{pH} 3$. Other influences on gastric $\mathrm{pH}$ include pathophysiological conditions and individual variations. Therefore, it is important to explore the drug release behavior at the $\mathrm{pH}$ higher than 3 and lower than 7.4. To this end, we evaluate the potential of employing APTES- $\mathrm{Fe}_{3} \mathrm{O}_{4}$ nanoparticles as a drug delivery system for ciprofloxacin and ofloxacin.

\section{Effect of pH}

The coating technique is the main approach used to synthesis of $\mathrm{pH}$ dependent drug delivery vehicles and it is most suitable for water soluble drugs. The release profiles of ciprofloxacin and ofloxacin was studied in different buffered $\mathrm{pH}(5.5,6.0,7.2,8.0,8.5$ and 9.0). The results were achieved after $2 \mathrm{~h}$ at $25^{\circ} \mathrm{C}$ and shown in Figure 10. As seen, the maximum release occurred in $\mathrm{pH} 8.0$ for both drugs. In this $\mathrm{pH}$, the ammonium groups of APTES became deprotonized and became in the form of $\mathrm{NH}_{2}$ and carboxylic acid groups of the drug remain in the $\mathrm{COO}^{-}$form simultaneously. It is known that the ionizable drugs that contain at least one acidic or basic group in their structure are more soluble in charged form and their aqueous solubility is $\mathrm{pH}$-dependent [28]. Thus, the release of the drug is increased in higher $\mathrm{pH}$. Since we have to perform the experiments in body conditions; we select the $\mathrm{pH}$ 5.5 and 7.2 for further studies.

\section{Effect of temperature}

Sensitivity of a system to temperature is one of the most characteristics in controlled drug delivery. The effect of temperature on the drug release has been investigated in two different acidity solutions with $\mathrm{pH} 5.5$ and 7.2. The results are summarizing in Table 2. As seen, the drug release increase with increasing temperature and was highest at $40^{\circ} \mathrm{C}$. Higher mobility along with decreasing in medium viscosity may one of the reasons for this observation. In addition, increase in

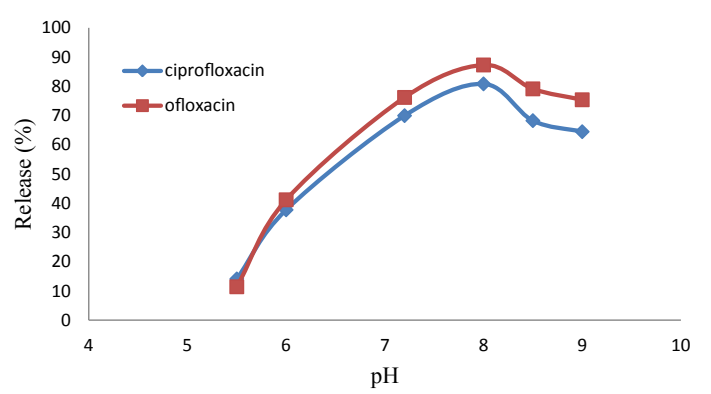

Figure 10: Release profiles of ofloxacin and ciprofloxacin at different $\mathrm{pH}$.

\begin{tabular}{|c|c|c|c|c|}
\hline \multirow{2}{*}{ Temperature $\left.\mathbf{(}^{\circ} \mathbf{C}\right)$} & \multicolumn{2}{|c|}{ ciprofloxacin } & \multicolumn{2}{c|}{ ofloxacin } \\
\cline { 2 - 5 } & $\mathrm{pH} 5.5$ & $\mathrm{pH} \mathrm{7.2}$ & $\mathrm{pH} 5.5$ & $\mathrm{pH} 7.2$ \\
\hline 25 & 14.1 & 69.95 & 11.41 & 76.18 \\
\hline 37 & 16.69 & 77.46 & 12.13 & 80.04 \\
\hline 40 & 17.73 & 79.20 & 14.83 & 81.89 \\
\hline
\end{tabular}

Table 2: Release (\%) of ciprofloxacin and ofloxacin at different Temperature and $\mathrm{pH}$.
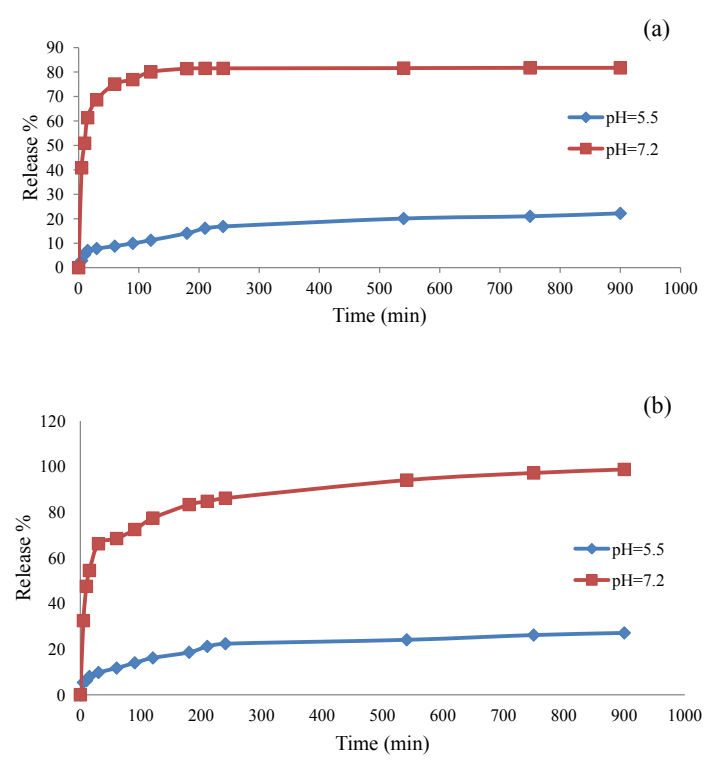

Figure 11: In vitro release profile of (a) Ofloxacin and (b) Ciprofloxacin at $\mathrm{pH}$ 5.5 and 7.2 .

temperature may speed up the rate of $\mathrm{H}$-bonding dissociation between carboxylate negative charged groups of the drug and ammonium positive charged groups of APTES. Same reason as the $\mathrm{pH}$, temperature of $37^{\circ} \mathrm{C}$ was selected for further studies.

\section{Release behavior}

The release behavior of both drugs was carried out under simulated physiological conditions (temperature is $37^{\circ} \mathrm{C}$ and $\mathrm{pH} 5.5$ and 7.2) with significant differences in release rate when $\mathrm{pH}$ varies from acidic in the stomach ( $\mathrm{pH}$ 5.5) to slightly alkaline in the intestine ( $\mathrm{pH} 7.2$ ). In vitro release profiles of the drugs are shown in Figure 11. As seen, the release of both drugs was rapid within first 30 min (nearly $69 \%$ for ofloxacin and $67 \%$ for ciprofloxacin) at $\mathrm{pH} 7.2$. This can be attributed to the hydrolysis of amine group in the drugs. Finally, after $12 \mathrm{~h}$ about $81.7 \%$ of ofloxacin and $98.8 \%$ of ciprofloxacin were released. On the other hand, at $\mathrm{pH} 5.5$, only $22.2 \%$ of ofloxacin and $27.1 \%$ of ciprofloxacin were released. As mentioned above, the first $\mathrm{pK}_{\mathrm{a}}$ of both drugs are about 6 and below this $\mathrm{pH}$ carboxyl groups are in the form of $-\mathrm{COOH}$. Thus, the intermolecular H-bonding between drugs and APTES-coated nanopatricles block the drug release from the particles. Hence the release of these drugs in acidic medium such as stomach, decreases and increases at neutral $\mathrm{pH}$ of intestine. From the more practical point of view, the APTES- $\mathrm{Fe}_{3} \mathrm{O}_{4}$ nanoparticles can overpass the acidic medium of gastric fluid with virtually no drug release, and then release the most of the drugs in intestine fluids. 
Citation: Mashhadizadeh MH, Amoli-Diva M (2012) Drug-Carrying Amino Silane Coated Magnetic Nanoparticles as Potential Vehicles for Delivery of Antibiotics. J Nanomed Nanotechol 3:139. doi:10.4172/2157-7439.1000139

Page 7 of 7

\begin{tabular}{|c|c|c|c|c|c|c|c|c|}
\hline \multirow{2}{*}{ Drug } & \multicolumn{2}{|c|}{ Zero-order } & \multicolumn{2}{|c|}{ First order } & \multicolumn{2}{|c|}{ Higuchi } \\
\cline { 2 - 7 } & $\mathrm{K}$ & $\mathrm{R}^{2}$ & $\mathrm{~K} \times 10^{4}$ & $\mathrm{R}^{2}$ & $\mathrm{~K}$ & $\mathrm{R}^{2}$ & $\mathrm{~K}$ \\
\hline Ciprofloxacin & 0.05 & 0.604 & 4.342162 & 0.951 & 1.95 & 0.805 & 0.002 \\
\hline Ofloxacin & 0.15 & 0.648 & 4.342162 & 0.768 & 2.91 & 0.826 \\
\hline
\end{tabular}

Table 3: Results for different release mechanisms for ciprofloxacin and ofloxacin.

\section{Kinetic modeling of drug release}

The drug release data were fitted to different models in an attempt to establish the kinetics and release mechanisms. Modeling was limited to four models that are commonly applied to drug release data from solid dosage forms. Korsmeyer-Peppas model dose not mentioned here because it is used commonly for polymeric matrix. Table 3 shows the correlation coefficient and rate constant of different kinetic models which are the main factors in choosing the best fit model. As could be observed, the first-order and Higuchi models found to be the best fitted for ciprofloxacin and ofloxacin release respectively, indicating that drug release mechanism was diffusion controlled $[29,30]$.

\section{Conclusion}

The APTES -coated $\mathrm{Fe}_{3} \mathrm{O}_{4}$ nanoparticles were synthesized as a simple drug carrier system for delivery of two antibiotics, ofloxacin and ciprofloxacin. The loading kinetics and capacity of the two drugs were measured and the results showed good loading capacity for the two drugs. The effect of $\mathrm{pH}$ and temperature on the release of the two drugs was investigated. The drug-loaded nanoparticles showed $\mathrm{pH}$-triggered release of drugs with higher release rate at $\mathrm{pH}$ of 7.2 compared to lower $\mathrm{pH}$ of 5.5 and followed first-order and Higuchian kinetics for ciprofloxacin and oflaxacin respectively, confirming that it can be used as a good drug carrying vehicle for delivery of two antibiotics in neutral medium. In addition, one of the proposed applications for this drug carrier is the injection of the carrier to the muscles. This can causes the nano-carrier experience neutral medium without passing through the acidic stomach medium and release the drugs gradually within 12 hours. We have revealed that feasibility of using APTES coated $\mathrm{Fe}_{3} \mathrm{O}_{4}$ nanoparticles as a carrier for controlled drug delivery. In future works, the use of $\mathrm{pH}$-responsive polymers as coating materials was studied to extend the range of $\mathrm{pH}$ applied for these antibiotics.

\section{References}

1. Orive G, Hernandez RM, Rodriguez Gascon A, Dominguez-Gil A, Pedraz JL (2003) Drug delivery in biotechnology: present and future. Curr Opin Biotechnol 14: $659-664$

2. Langer $R$ (1990) New methods of drug delivery. Science 249: 1527-1533.

3. Parveen S, Misra R and Sahoo SK (2012) Nanoparticles: a boon to drug delivery, therapeutics, diagnostics and imaging. Nanomedicine 8: 147-166.

4. Yih TC and Al-Fandi M (2006) Engineered nanoparticles as precise drug delivery systems. J Cell Biochem 97: 1184-1190.

5. Yordanov G (2012) Development of cephalexin-loaded poly (ethyl cyanoacrylate) colloidal nanospheres. Central European Journal of Chemistry 10: 305-312.

6. Dutta N, Green D (2008) Nanoparticle stability in semidilute and concentrated polymer solutions. Langmuir 24: 5260-5269.

7. Lallana E, Sousa-Herves A, Fernandez-Trillo F, Rigger R, Fernandez-Megia E (2012) Click Chemistry for Drug Delivery Nanosystems. Pharm Res 29: 1-34.

8. Dobson J (2006) Magnetic micro- and nano-particle-based targeting for drug and gene delivery. Nanomedicine (Lond) 1: 31-37.

9. Gupta AK, Gupta M (2005) Synthesis and surface engineering of iron oxide nanoparticles for biomedical applications. Biomaterials 26: 3995-4021.

10. Morel AL, Nikitenko SI, Gionnet K, Wattiaux A, Lai-Kee-Him J, et al. (2008) Sonochemical Approach to the Synthesis of $\mathrm{Fe}_{3} \mathrm{O}_{4} @ \mathrm{SiO}_{2}$ Core-Shell
Nanoparticles with Tunable Properties. ACS Nano 2: 847-856.

11. Smith EA, Chen W (2008) How to Prevent the Loss of Surface Functionality Derived from Aminosilanes. Langmuir 24: 12405-12409.

12. Wu W, He Q, Chen H, Tang J, Nie L (2007) Sonochemical synthesis, structure and magnetic properties of air-stable $\mathrm{Fe}_{3} \mathrm{O}_{4} / \mathrm{Au}$ nanoparticles. Nanotechnology 18: $145609-145613$

13. Bruce IJ, Sen T (2005) Surface modification of magnetic nanoparticles with alkoxysilanes and their application in magnetic bioseparations. Langmuir 21 7029-7035.

14. Cao H, He J, Deng L, Gao X (2009) Fabrication of cyclodextrin-functionalized superparamagnetic $\mathrm{Fe}_{3} \mathrm{O}_{4}$ /amino-silane core-shell nanoparticles via layer-bylayer method. Appl Surf Sci 255: 7974-7980.

15. Mashhadizadeh $\mathrm{MH}$, Karami Z (2011) Solid phase extraction of trace amounts of $\mathrm{Ag}, \mathrm{Cd}, \mathrm{Cu}$, and $\mathrm{Zn}$ in environmental samples using magnetic nanoparticles coated by 3-(trimethoxysilyl)-1-propantiol and modified with 2-amino-5mercapto-1,3,4-thiadiazole and their determination by ICP-OES. J Hazard Mater 190: 1023-1029.

16. Yamaura M, Camilo RL, Sampaio LC, Macedo MA, Nakamura M, et al. (2004) Preparation and characterization of (3-aminopropyl)triethoxysilane-coated magnetite nanoparticles. J Magn Magn Mater 279: 210-217.

17. Qu J, Liu G, Wang Y, Hong R (2010) Preparation of $\mathrm{Fe}_{3} \mathrm{O}_{4}$-chitosan nanoparticles used for hyperthermia. Adv Powder Technol 21: 461-467.

18. Skinner BJ, Appleman DE (1963) Melanophlogite, a cubic polymorph of silica. AM Mineral 48: 854-867.

19. Zhang JL, Srivatava RS, Misara RDK (2007) Core-Shell Magnetite nanoparticles surface encapsulated with smart stimuli-responsive polymer: synthesis, characterization, and LCST of viable drug-targeting delivery system. Langmuir 23: 6342-6351.

20. Pisal S, Zainnuddin R, Nalawade P, Mahadik K, Kadam S (2004) Molecular properties of ciprofloxacin-indion 234 complexes. AAPS PharmSciTech 5: 84 91.

21. Zaidi SA, Han KM, Kim SS, Hwang DG, Cheong WJ (2009) Open tubular layer of S-ofloxacin imprinted polymer fabricated in silica capillary for chiral CEC separation. J Sep Sci 32: 996-1001.

22. Carre A, Birch W, Lacarriere V (2007) Glass substrates modified with organosilanes for DNA immobilization. Silanes and Other Coupling Agents 4 1-14.

23. Vansant EF, Voort P, Vrancken KC (1995) Characterization and chemica modification of the silica surface. Elsevier, Netherlands.

24. Pan BF, Gao F, Gu HC (2005) Dendrimer modified magnetite nanoparticles for protein immobilization. J Colloid Interface Sci 284: 1-6.

25. Yang $X$, Zhang $X$, Ma $Y$, Huang $Y$, Wang $Y$, Chen $Y$ (2009) Superparamagnetic graphene oxide- $\mathrm{Fe}_{3} \mathrm{O}_{4}$ nanoparticles hybrid for controlled targeted drug carriers. J Mater Chem 19: 2710-2714.

26. Zhang Y, Zhang Q, Zha L, Yang W, Wang C, et al. (2004) Preparation, characterization and application of pyrene-loaded methoxy poly(ethylene glycol)-poly(lactic acid) copolymer nanoparticles. Colloid Polym Sci 282: 13231328.

27. Zhu L, Ma J, Jia N, Zhao Y, Shen H (2008) Chitosan-coated magnetic nanoparticles as carriers of 5-Fluorouracil: Preparation, characterization and cytotoxicity studies. Colloids Surf B 68: 1-6.

28. Völgyi G, Baka E, Box KJ, Comer JE, Takács-Novák K (2010) Study of pHdependent solubility of organic bases. Revisit of Henderson-Hasselbalch relationship. Anal Chim Acta 673: 40-46.

29. Dash S, Murthy PN, Nath L, Chowdhury P (2010) Kinetic modeling on drug release from controlled drug delivery systems. Acta Pol Pharm 67: 217-223.

30. Grassi M, Grassi G (2005) Mathematical Modelling and Controlled Drug Delivery: Matrix Systems. Curr Drug Deliv 2: 97-116. 